\section{AB1170 A PHASE IV, MULTICENTER, SINGLE-ARM, OPEN- LABEL STUDY TO EVALUATE THE IMPACT OF APREMILAST ON HAND AND WHOLE-BODY MRI OUTCOMES IN PATIENTS WITH PSORIATIC ARTHRITIS (MOSAIC): RATIONALE, DESIGN AND METHODS}

Mikkel Ǿstergaard ${ }^{1}$, Walter P. Maksymowych ${ }^{2}$, Mikael Boesen ${ }^{3}$, Olga Kubassova ${ }^{4}$, Priscila Nakasato ${ }^{5}$, Benoit Guerette ${ }^{5}$, Lichen Teng ${ }^{5}$, Philip J. Mease ${ }^{6}{ }^{1}$ University of Copenhagen, Copenhagen, Denmark; ${ }^{2}$ University of Alberta, Edmonton, Canada; ${ }^{3}$ Bispebjerg and Frederiksberg Hospital, Copenhagen, Denmark; ${ }^{4}$ Image Analysis Group, London, United Kingdom; ${ }^{5}$ Celgene Corporation, Summit, United States of America; ${ }^{6}$ Swedish Medical Center and University of Washington School of Medicine, Seattle, United States of America

Background: Phase III clinical trials have shown apremilast (APR) reduced PsA signs/symptoms and improved physical function, ${ }^{1-3}$ but no study has addressed its impact on structural disease progression. MRI is a highly sensitive, validated tool to assess inflammatory and structural changes, as it can detect soft tissue inflammation, bone marrow edema (BME) lesions, bone erosion and proliferation in peripheral joints and axial skeleton. Whole-body (WB)-MRI, a relatively novel technique in musculoskeletal studies, allows assessment of all peripheral/axial joints and entheses in 1 examination. ${ }^{4}$ Recent, consensus-based and semi-quantitative scoring methods were developed and validated. This study is the first to systematically use new state-of-the-art MRI scoring methodologies to assess PsA inflammatory and structural changes in a global clinical trial. Objectives: To assess APR efficacy on inflammatory indices and imaging outcome measures associated with PsA structural progression by conventional static MRI and dynamic contrast-enhanced (DCE)-MRI of the most affected hand and WB-MRI.

Methods: The study aims to enroll 120 biologic-naïve adults with PsA for $>3$ mos to $\leq 5$ yrs and prior treatment with $\leq 2$ conventional DMARDs. Subjects must have $>3$ swollen and $>3$ tender joints, hand involvement ( $\geq 1$ swollen joint or $\geq 1$ dactylitis) and $\geq 1$ active enthesitis site. After 4wk screening, all eligible patients will receive APR $30 \mathrm{mg}$ twice daily (titrated during the first 5 days) as monotherapy or in combination with methotrexate for 48 wks, with a 4-wk observational follow-up. Conventional MRI and optional DCE-MRI of the most affected hand and WBMRI of the entire body will be performed at Wks 0,24 and 48. The primary endpoint is change from BL to Wk 24 in OMERACT PsA MRI (PsAMRIS) composite score of BME + synovitis + tenosynovitis. Other imaging endpoints include change from $\mathrm{BL}$ to Wk 48 in PsAMRIS composite score (BME + synovitis + tenosynovitis) and change from BL to Wks 24 and 48 in PsAMRIS composite score (BME + synovitis), PsAMRIS composite inflammation score (BME + synovitis + tenosynovitis + periarticular inflammation), PsAMRIS total damage score (erosion + bone proliferation), WB-MRI indices (including peripheral joint inflammation index and peripheral enthesis inflammation index), hip and knee inflammation MRI scores (HIMRISS, KIMRISS), OMERACT heel enthesitis MRI indices, axial inflammation indices (SPARCC, CanDen), DEMRIQ-Volume and DEMRIQ-Inflammation and other DCE-MRI-derived parameters. Clinical parameters will include SJC/TJC, CDAPSA, SPARCC Enthesitis Index, Leeds Enthesitis Index, Leeds Dactylitis Index, PASDAS, PtGA, PhGA, Patient's Assessment of Pain, HAQ-DI, and BASDAI and impact of disease (PsAID12). Safety and tolerability also will be assessed.

Results: The study protocol was approved by an independent ethics committee and is now enrolling in the USA. Selected countries in Europe and Russia will also participate. MRI, clinical and patient-reported outcomes will be analyzed.

Conclusion: This study will provide important evidence of APR's impact on inflammatory/structural changes by assessing all PsA musculoskeletal domains (peripheral arthritis, enthesitis, dactylitis and axial disease). Furthermore, it will yield information on use of conventional MRI-, WB-MRIand DCE-MRI-driven outcome measures in PsA clinical trials.

\section{REFERENCES}

[1] Kavanaugh 2014. 2. Cutolo 2016. 3. Edwards 2016. 4. Østergaard 2017.

Disclosure of Interests: Mikkel Ǿstergaard Grant/research support from: Abbvie, Celgene, Centocor, Merck, Novartis, Consultant for: Abbvie, BMS, Boehringer-Ingelheim, Celgene, Eli Lilly, Hospira, Janssen, Merck, Novartis, Novo, Orion, Pfizer, Regeneron, Roche, and UCB, Speakers bureau: Abbvie, BMS, Boehringer-Ingelheim, Celgene, Eli Lilly, Hospira, Janssen, Merck, Novartis, Novo, Orion, Pfizer, Regeneron, Roche, and UCB, Walter P Maksymowych Grant/research support from: AbbVie, Pfizer, Janssen, Novartis, Consultant for: AbbVie, Eli Lilly, Boehringer, Galapagos, Janssen, Novartis, Pfizer and UCB Pharma; Chief Medical Officer for Canadian Research and Education Arthritis, Mikael Boesen Shareholder of:
Image Analysis Group, UK, Grant/research support from: Image Analysis Group, UK, OAK Foundation, EUROSTAR, Consultant for: Esaote, El Lilly, Celgene, Carestream, UCB, Abbvie, Pfizer, Astra Zeneka, Roche Siemens, Image Analysis Group, Olga Kubassova Shareholder of: IAG, Image Analysis Group, Employee of: IAG, Image Analysis Group, Priscila Nakasato Employee of: Celgene Corporation, Benoit Guerette Employee of: Celgene Corporation, Lichen Teng Employee of: Celgene Corporation, Philip J Mease Grant/research support from: AbbVie, Amgen, BMS, Celgene, Janssen, Lilly, Novartis, Pfizer, SUN and UCB, Consultant for: AbbVie, Amgen, BMS, Galapagos, Gilead Sciences, Inc., Janssen, Lilly, Novartis, Pfizer, SUN and UCB, Speakers bureau: AbbVie, Amgen, BMS, Celgene, Genentech, Janssen, Lilly, Novartis, Pfizer and UCB DOI: 10.1136/annrheumdis-2019-eular.1368

\section{AB1171 COMPUTER-BASED EVALUATION OF JOINT SPACE NARROWING IN PATIENTS WITH RHEUMATOID ARTHRITIS TREATED WITH WITH CERTOLIZUMAB PEGOL}

Alexander Pfeil ${ }^{1}$, Anica Nussbaum ${ }^{1,2}$, Diane Renz ${ }^{2}$, Ansgar Malich $^{3}$, Joachim Böttcher ${ }^{4}$, Gunter Wolf ${ }^{1}$, Peter Oelzner ${ }^{1} .{ }^{1}$ Jena University Hospital Friedrich Schiller University Jena, Department of Internal Medicine III, Jena, Germany, ${ }^{2}$ Jena University Hospital - Friedrich Schiller University Jena, Jena, Germany, ${ }^{3}$ Suedharz Klinikum Nordhausen, Institute of Diagnostic and Interventional Radiology, Nordhausen, Germany; ${ }^{4}$ SRH Waldklinikum Gera, Institute of Diagnostic and Interventional Radiology, Gera, Germany

Background: The reduction of finger joint space width in patients with rheumatoid arthritis (RA) is associated with joint destruction. Anti-TNF treatment with certolizumab pegol is an effective therapy in RA-patients The computer-assisted joint space analysis is a new computer based technique to measure joint space width on hand radiographs.

Objectives: The aim of this post-hoc analysis of the data set used in the RAPID 1 trial was to quantify finger joint space width of RA patients treated with Certolizumab pegol.

Methods: The post-hoc analysis includes 328 patients. These patients were divided into three groups: methotrexate plus placebo, certolizumab pegol $200 \mathrm{mg}$ (every two weeks) plus methotrexate, and certolizumab pegol $400 \mathrm{mg}$ (every two weeks) plus methotrexate. All patients underwent $\mathrm{x}$-rays of the hand at baseline and week 52 as well as the quantification of finger joint space width of the metacarpal-phalangeal articulations (MCP) using the computer-assisted joint space analysis (Version 1.3.6; Sectra; Sweden). The joint space distance is expressed as mean joint space width of the MCP joints I to V (JSD-MCP total)

Results: The methotrexate group presented a significant joint space reduction with $-4.8 \%$ for JSD-MCP total from $0.151 \pm 0.028 \mathrm{~cm}$ (baseline) to $0.144 \pm 0.033 \mathrm{~cm}$ (week 52). For the patients treated with certolizumab pegol $400 \mathrm{mg}$ a non-significant change $(0.6 \%)$ of JSD-MCP total from $0.146 \pm 0.034 \mathrm{~cm}$ (baseline) to $0.147 \pm 0.036 \mathrm{~cm}$ (week 52) was observed. A similar result was evaluated for the certolizumab pegol 200 $\mathrm{mg}$ group (JSD-MCP total: $0.147 \pm 0.035 \mathrm{~cm}$ [baseline] to $0.147 \pm 0.036$ $\mathrm{cm}$ [week 52]).

Conclusion: The study highlights that patients treated with certolizumab pegol plus methotrexat show no change of joint space width of the metacarpal-phalangeal articulations in comparison to patients with methotrexate plus placebo estimated by computer-assisted joint space analysis. Consequently, the automatic quantification of finger joint space is a sensitive technique for the quantification of joint space reduction and treatment monitoring.

\section{REFERENCES}

[1] Keystone E, Heijde Dv, Mason D Jr, et al. Certolizumab pegol plus methotrexate is significantly more effective than placebo plus methotrexate in active rheumatoid arthritis: findings of a fifty-two-week, phase III, multicenter, randomized, double-blind, placebo-controlled, parallel-group study Arthritis Rheum 2008:58:3319-29.

Disclosure of Interests: Alexander Pfeil Grant/research support from: This study is a part of the Investigator Initiated Study "The quantification of inflammatory related periarticular bone loss in certolizumab pegol treated patients with rheumatoid arthritis" which is funded and supported by UCB Pharma GmbH, Monheim, Germany (number: IIS-2014-101458)., Anica Nussbaum: None declared, Diane Renz: None declared, Ansgar Malich None declared, Joachim Böttcher: None declared, Gunter Wolf: None declared, Peter Oelzner: None declared DOI: 10.1136/annrheumdis-2019-eular.4061 